\title{
Fiber-optical accelerometers based on polymer optical fiber Bragg gratings
}

\author{
Yuan, Scott Wu; Stefani, Alessio; Bang, Ole; Andresen, Søren; Jacobsen, Torben; Nielsen, Finn Kryger; \\ Jacobsen, Torben; Rose, Bjarke; Herholdt-Rasmussen, Nicolai
}

\author{
Published in: \\ proceedings Optics and Photonics Congress
}

\section{Publication date:}

2010

Document Version

Publisher's PDF, also known as Version of record

Link back to DTU Orbit

Citation (APA):

Yuan, S. W., Stefani, A., Bang, O., Andresen, S., Jacobsen, T., Nielsen, F. K., Jacobsen, T., Rose, B., \& Herholdt-Rasmussen, N. (2010). Fiber-optical accelerometers based on polymer optical fiber Bragg gratings. In proceedings Optics and Photonics Congress (pp. SWA5). Optical Society of America (OSA). http://www.ihq.unikarlsruhe.de/events/congresses/2010/OSA/congress.shtml

\section{General rights}

Copyright and moral rights for the publications made accessible in the public portal are retained by the authors and/or other copyright owners and it is a condition of accessing publications that users recognise and abide by the legal requirements associated with these rights.

- Users may download and print one copy of any publication from the public portal for the purpose of private study or research.

- You may not further distribute the material or use it for any profit-making activity or commercial gain

- You may freely distribute the URL identifying the publication in the public portal 


\title{
Fiber-optical accelerometers based on polymer optical fiber Bragg gratings
}

\author{
Wu Yuan ${ }^{1, *}$, Alessio Stefani ${ }^{1}$, Ole Bang ${ }^{1}$, Søren Andresen ${ }^{2}$, Finn Kryger Nielsen ${ }^{2}$, \\ Torben Jacobsen ${ }^{3}$, Bjarke Rose ${ }^{3}$, Nicolai Herholdt-Rasmussen ${ }^{3}$ \\ ${ }^{1}$ DTU Fotonik, Dept. of Photonics Engineering, Technical University of Denmark, \\ DK-2800 Kgs. Lyngby, Denmark \\ wyuan@fotonik.dtu.dk \\ ${ }^{2}$ Brüel \& Kjær Sound \& Vibration Measurements A/S, Skodsborgvej 307, \\ DK-2850 Ncerum, Denmark \\ ${ }^{3}$ Ibsen Photonics A/S, Ryttermarken 15-21, DK-3520, Farum, Denmark
}

\begin{abstract}
Fiber-optical accelerometers based on polymer optical fiber Bragg gratings (FBGs) are reported. We have written $3 \mathrm{~mm}$ FBGs for $1550 \mathrm{~nm}$ operation, characterized their temperature and strain response, and tested their performance in a prototype accelerometer.

(C)2010 Optical Society of America

OCIS codes: (060.2310) Fiber optics; (060.2370) Fiber optics sensors; (060.3735) Fiber Bragg gratings
\end{abstract}

\section{Introduction}

Polymer Optical Fibers (POFs) made of polymethyl methacrylate (PMMA) have a low Young's Modulus of 3.2GPa compared to the $72 \mathrm{GPa}$ of Silica [1]. Bragg gratings written into PMMA POFs could therefore be ideal as the sensing element in fiber-optical accelerometers, because they potentially could provide better sensitivity and a wider dynamic range than silica fibers [2-4]. This of course requires that the length of the PMMA POF is short, due to the large loss of PMMA, and that one does not want to operate at high temperature, due to the low melting temperature of PMMA.

In order to maximize the sensitivity and the dynamic range of an accelerometer based on FBGs, the outer diameter and the length of the sensing fiber segment should be as small as possible. To this end the phase-mask technique and a $325 \mathrm{~nm} \mathrm{HeCd} \mathrm{cw}$ laser have been used to fabricate $3 \mathrm{~mm}$ FBGs in a commercial PMMA singlemode step-index POF of diameter 115 micron from Paradigm Optics. To minimize the loss problem of PMMA, we have used $1 \mathrm{~cm}$ POF sections with FBGs in the center and glued them to standard Silica SMF-28 fibers. We use the Paradigm POF directly and we try to anneal it before use, in order to check whether the annealing improves its properties. The annealing is done at $80^{\circ} \mathrm{C}$ over 2 days. The POF FBGs have been characterized in terms of temperature and strain to find operating regimes with no hysteresis and loss of reflection. Our experiments show that annealing the POF FBG can offer more stable and linear performance at both higher temperatures and larger strain.

A prototype accelerometer, equipped with our $3 \mathrm{~mm}$ POF FBG, has been designed. It will be characterized by a fast commercial wavelength interrogator $(\mathrm{kHz})$ to track the response of the $\mathrm{FBG}$ to external vibrations.

\section{Experimental results}

The temperature response of a $3 \mathrm{~mm}$ grating in both an annealed POF and a normal POF, is shown in Fig. 1(a) and 1(b), respectively. The grating section of the polymer fiber was heated up with a resistive hot stage. A thermo couple was used to measure the real temperature around the polymer grating with an uncertainty around $0.3^{\circ} \mathrm{C}$. All gratings were fabricated with the same exposure time of 60 minutes. Twenty minutes was allowed for the temperature of the grating to stabilize at each new temperature setting before the resonance wavelengths and the peak intensity were measured [2,3]. A linear response is observed up to a critical temperature of $60^{\circ} \mathrm{C}$ in the normal POF. By annealing the POF we see that the critical temperature is increased to about $80^{\circ} \mathrm{C}$. In both cases the sensitivity below the critical temperature is about $-100 \mathrm{pm} /{ }^{\circ} \mathrm{C}$.

Two new gratings were temperature-cycled to study hysteresis. First we heat them up to $75^{\circ} \mathrm{C}$ and $55^{\circ} \mathrm{C}$, respectively (red dots), followed by cooling down to room temperature (red triangles). These temperatures are below the critical temperature and as expected we see in Figs. 1(a-b) a linear response and no hysteresis. Then we heat both up to $85^{\circ} \mathrm{C}$ (black squares), which is above the critical temperature, followed by cooling down to room temperature (black triangles). Now we observe a marked hysteresis of the resonance wavelength at room temperature. For the annealed POF we measure a permanent shift in the resonance wavelength of about $-4 \mathrm{~nm}$ (Fig. 
1(a)), but there is no noticeable drop in the reflected peak intensity (not shown). For the normal POF the shift is 5 times stronger, about $-20 \mathrm{~dB}$ (Fig. 1(b)) and there is a drop of $6 \mathrm{~dB}$ in the reflected peak intensity.

We have also characterized the static strain response of the POF FBGs. The ends of the POF were clamped to two micro-translation stages. One stage was fixed and used to butt-couple the POF to the silica fiber. The other stage can move longitudinally to manually apply axial strain to the grating with a low loading speed [3]. The gratings were left to stabilize for about 10 minutes each time the tensile strain was changed, before measuring the reflection spectrum. The results are shown in Figs. 1(c-f). In Figs. 1(c-d) we see that the wavelength sensitivity is approximately constant over the shown strain region, with a value of about at $1.37 \mathrm{pm} / \mu \varepsilon$ and $1.30 \mathrm{pm} / \mu \varepsilon$ for the annealed and normal POF, respectively. In contrast, the reflected peak intensity drops suddenly above a certain critical strain, which is increased from about $2.5 \%$ to $3.0 \%$ by annealing the fiber.

A strain loading cycle experiment was carried out in order to examine whether any hysteresis could be detected. The POF FBG's were stretched by $3.75 \%$ and released again. The results, shown in Figs. 1(e-f), showed no noticeable hysteresis for the annealed fiber, whereas the normal POF showed a small difference in the resonance wavelength of about $3 \mathrm{~nm}$.
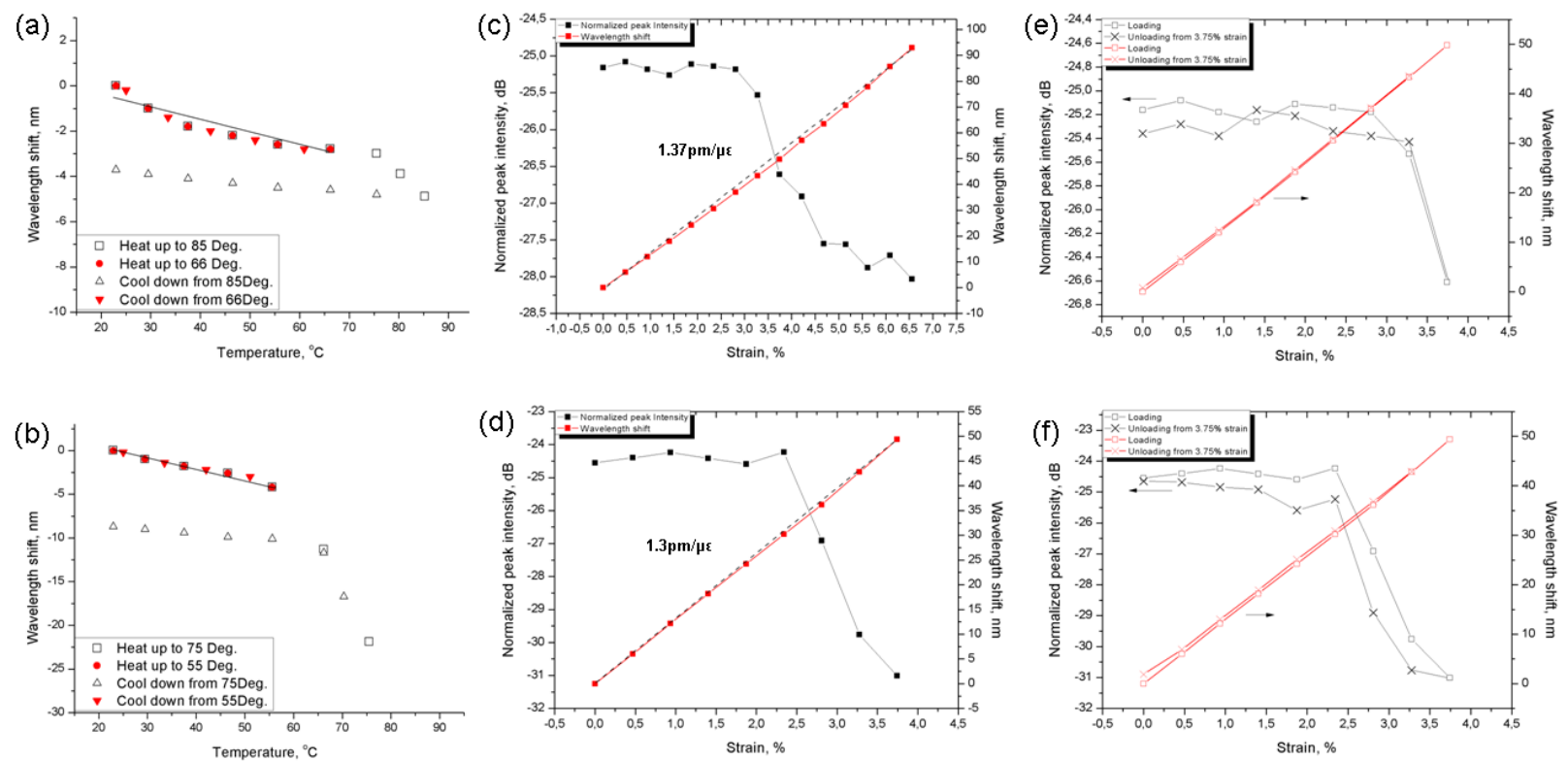

Fig. 1. (a-b) Bragg wavelength versus temperature during heating and cooling cycles. (c-d) Strain sensitivity of Bragg wavelength and reflected peak intensity. (e-f) Same strain sensitivity during loading with 3.75\% strain and downloading again. Top row shows the annealed POF. Bottom row shows the normal POF.

\section{Future work}

A prototype vibration/acceleration sensor equipped with 3mm POF FBGs has been designed as sketched in Fig. 2.

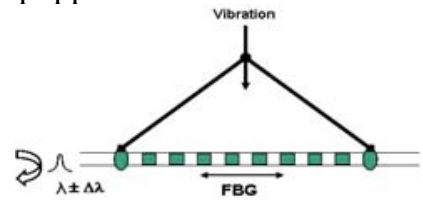

Fig.2. Sketch of the vibration sensor that will be characterized in terms of its dynamic response.

Preannealing the fiber can greatly optimize the performance of POF FBGs and at the same time keep all the advantages of POFs. The prototype vibration sensors using $3 \mathrm{~mm}$ POF FBGs will be characterized by a commercial fast wavelength interrogator $(\mathrm{KHz})$, to track the dynamic response of the thin POF FBGs to the longitudinal strain imposed on it by a transducer element, as a result of acceleration. The design will be optimized for maximum gain sensitivity and dynamic range. New POF FBGs with resonance wavelength around 850nm will also be explored.

\section{References}

1. M.C.J. Large. L. Poladian, G.W. Barton, M.A. van Eijkelenborg, "Microstructured Polymer Optical Fibers" (Springer, 2008).

2. H.Y. Liu, G.D. Peng, P.L. Chu, “Thermal tuning of polymer optical fiber bragg gratings,” IEEE Photon. Technol. Lett., 13, 824-826, (2001). 
3. K. Carroll, C. Zhang, D. J. Webb, K. Kalli, A. Argyros, M.C.J. Large, "Thermal response of Bragg gratings in PMMA microstructured optical fibers," Opt. Express., 15, 8844-8850, (2007).

4. H.Y. Liu, H.B. Liu, G.D. Peng, “Tensile strain characterization of polymer optical fibre Bragg gratings,” Opt. Commun., 251, 37-43, (2005). 